Article

\title{
Protection of Piglets with Maternally Derived Antibodies from Sows Inoculated with an Attenuated Live Marker Classical Swine Fever Vaccine (Flc-LOM-BE ${ }^{\text {rns }}$ )
}

\author{
SeEun Choe ${ }^{1,+}{ }^{,}$Jihye Shin ${ }^{1,+}{ }^{+}$Ki-Sun Kim ${ }^{1}$, Sok Song ${ }^{1}$, Ra Mi Cha ${ }^{1}$, Byung-Il Jung ${ }^{2}$, \\ Bang-Hun Hyun ${ }^{1}$, Bong-Kyun Park ${ }^{1,3}$ and Dong-Jun An 1,* \\ 1 Virus Disease Division, Animal and Plant Quarantine Agency, Gimchen, Gyeongbuk-do 39660, Korea; \\ ivvi59@korea.kr (S.C.); shinji227@korea.kr (J.S.); kisunkim@korea.kr (K.-S.K.); ssoboro9@korea.kr (S.S.); \\ rami.cha01@korea.kr (R.M.C.); hyunbh@korea.kr (B.-H.H.); parkx026@korea.kr (B.-K.P.) \\ 2 Korea Pork Producers Association, Seocho-gu, Seoul 06643, Korea; exksa001@daum.net \\ 3 College of Veterinary Medicine, Seoul University, Gwanak-ro, Gwanak-gu, Seoul 08826, Korea \\ * Correspondence: andj67@korea.kr; Tel.: +82-54-912-0795 \\ + These authors made an equal contribution.
}

Received: 29 April 2020; Accepted: 25 July 2020; Published: 27 July 2020

\begin{abstract}
Here, we investigated the protective efficacy provided by passive immunity induced by a classical swine fever (Flc-LOM-BE ${ }^{\mathrm{rns}}$ ) vaccine with the newly developed DIVA (Differentiating Infected from Vaccinated Animals) function. Ten pigs (aged 40-60 days) with maternally derived antibodies (MDAs) obtained from sows inoculated with the Flc-LOM-BE ${ }^{\text {rns }}$ vaccine were challenged with virulent classical swine fever virus (CSFV). Pigs with an MDA titer of $6 \log _{2}$ induced by the Flc-LOM-BE ${ }^{\text {rns }}$ vaccine were fully protected against virulent CSFV challenge but not the pigs with an MDA titer under $5 \log _{2}$. In addition, Flc-LOM-BE ${ }^{\text {rns }}$ vaccine-derived MDAs successfully differentiated vaccinated pigs by bovine viral diarrhea virus (BVDV) $\mathrm{E}^{\mathrm{rns}} / \mathrm{CSFV} \mathrm{E}^{\mathrm{rns}}$ antibody detection, functioning as a DIVA.
\end{abstract}

Keywords: CSFV; DIVA; Flc-LOM-BE ${ }^{\text {rns }}$ vaccine; MDA

\section{Introduction}

Classical swine fever virus (CSFV) is a member of the genus Pestivirus (family, Flaviviridae) [1-3]. CSFV harbors a single-stranded positive RNA genome comprising approximately 12,300 nucleotides. CSFV is classified into three different genotypes, which in turn comprise three or four sub-genotypes [1-3]. CSFV is a highly contagious, multi-systemic, hemorrhagic disease that is fatal to swine (Sus scrofa); it infects both breeding pigs and wild boars [1]. The development of DIVA (Differentiating Infected from Vaccinated Animals) vaccines, which make it possible to distinguishing vaccinated animals from infected animals, has drawn great attention [2]. A CSF live marker vaccine (Flc-LOM-BE ${ }^{\text {rns }}$ ) that functions as a DIVA was generated by inserting the Erns gene from bovine viral diarrhea virus (BVDV) into an infectious clone (Flc-LOM) derived from the LOM strain, which was used as a CSF vaccine in South Korea [4]. Pigs inoculated with Flc-LOM-BE ${ }^{\text {rns }}$ vaccine induced antibody against BVDV $E^{\text {rns }}$ but not CSFV $E^{\text {rns }}$. After virulent CSFV challenge, vaccine immunized pigs would have both antibodies against BVDV $E^{\text {rns }}$ and CSFV $E^{\text {rns }}$. Sows immunized with the Flc-LOM-BE ${ }^{\text {rns }}$ vaccine have been protected against vertical viral transmission of their fetus when challenged with virulent CSFV at the early, middle, and late period of pregnancy [4]. Lactogenic transfer of maternally derived antibodies (MDAs) from immunized sows is considered an effective and economic way to provide piglets with passive immunity against virus infection before they acquire active immunity via direct vaccination $[5,6]$. In piglets that have ingested low quantities of colostrum, vaccination induces a strong 
antigenic stimulus, which is characterized by a normal humoral immune response and resistance to subsequent virus challenge [7-13]. A number of studies have been conducted to investigate whether pigs that have passive antibodies obtained from colostrum can acquire active immunity after an attenuated live CSF vaccination [7,9]; unfortunately, limited studies were conducted to test the efficacy of passive immunity provided only by colostral antibodies against virulent virus challenge [11,14].

Therefore, the aim of this study is to investigate whether pigs that obtained various levels of MDAs from sows immunized with the Flc-LOM-BE ${ }^{\mathrm{rns}}$ vaccine are protected against subsequent challenge with virulent CSFV.

\section{Results}

\subsection{MDA Titer and RNA Copy Number}

Ten pigs that obtained MDAs from Flc-LOM-BE ${ }^{\text {rns }}$-vaccinated sows were divided into subgroups by their MDA levels: V1 ( $6 \log _{2}$ MDA), V2 (5 $\log _{2}$ MDA), V3 (4 $\log _{2}$ MDA), and V4 $\left(3 \leq \log _{2}\right.$ MDA) (Table 1). MDA levels of 10 pigs according to age of pig were as follows: 42-day-old pigs (6 $\log _{2}$ MDA), 40-day-old pigs (5 and $\left.6 \log _{2} \mathrm{MDA}\right), 46$-day-old pigs (5 $\left.\log _{2} \mathrm{MDA}\right), 53$-day-old pigs ( 4 and $5 \log _{2} \mathrm{MDA}$ ), and 60-day-old pigs ( $3 \leq \log _{2} \mathrm{MDA}$ ), respectively (Table 1). For the mock group, five pigs (48-day-old and 55-day-old) that obtained MDAs from unvaccinated sows with $3 \leq \log _{2}$ MDA (negative) were tested. The MDA levels of all pigs were obtained on the day of challenge and a threshold of $3 \leq \log _{2}$ was used to determine positive/negative based on serum neutralization titer.

Table 1. Viral copy number of pigs with maternally derived antibodies (MDA) from sows vaccinated with the Flc-LOM-BE ${ }^{\text {rns }}$ vaccine after challenge. CSFV: classical swine fever virus.

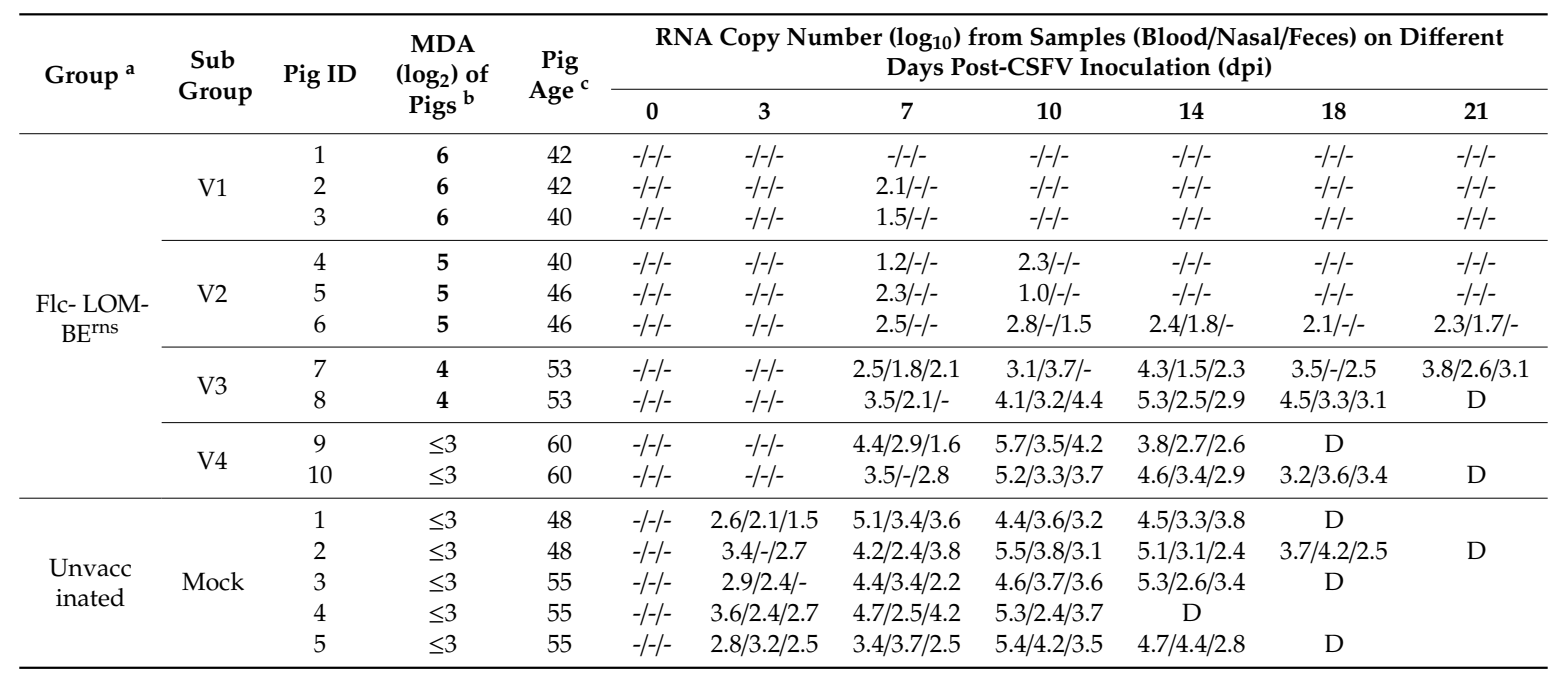

a Two groups of pigs (aged 40-60 days) receiving MDAs from sows immunized (or not) with Flc-LOM-BE ${ }^{\text {rns }}$ were challenged with virulent CSFV. Then, pigs were divided into subgroups based on their maternally derived antibody levels at the day of challenge: V1 $\left(6 \log _{2}\right.$ MDA), V2 $\left(5 \log _{2}\right.$ MDA), V3 $\left(4 \log _{2}\right.$ MDA), V4 $\left(3 \leq \log _{2}\right.$ MDA), and Mock $\left(3 \leq \log _{2} \mathrm{MDA}\right) .{ }^{\mathbf{b}} \mathrm{MDA}\left(\log _{2}\right)$ of pigs: MDA of pigs on the day of challenge. Positive and negative MDA of pigs on the day of challenge were marked with bold and normal letters, respectively. Threshold for positive and negative by the serum neutralization antibody test were set to $3 \log _{2}$. ${ }^{\mathrm{c}}$ Pig age: pig age on the day of challenge, D: dead, and -: no detection.

We have used slightly different aged pigs to obtain 4 different MDA levels to test the efficacy of passive immunity (Table 1). After challenge, CSF RNA was detected in only two blood samples (RNA copy number $=1.5$ and $2.1 \log _{10}$ ) from pigs in the V1 subgroup (at 7 days post inoculation, or dpi); however, no CSF RNA was detected in fecal or nasal samples during the 3-week observation period (Table 1). CSF RNA was detected in blood samples from two pigs in the V2 subgroup (at 7 and $10 \mathrm{dpi}$ ); viral RNA was detected in blood, nasal, and/or fecal samples from the remaining pigs from 7 to $21 \mathrm{dpi}$ 
(Table 1). CSF RNA was detected in almost all samples (blood, nasal, and fecal) from pigs in subgroups V3 and V4, and in all samples from mock group pigs, during the observation period (Table 1).

\subsection{Clinical Scores, Leucocyte Counts, Body Temperature Measurement, and Mortality}

All groups showed various clinical signs after inoculation with virulent CSFV. The mean clinical scores during the experimental period were as follows: 1 for subgroup V1, 4.3 for subgroup V2, 12.5 for subgroup V3, 17.5 for subgroup V4, and 19.4 for the mock group (Figure 1). The mean number of leucocytes after inoculation with virulent CSFV was as follows: V1 subgroup, no change; V2 subgroup, a small drop only $(8433 / \mu \mathrm{L})$ at $7 \mathrm{dpi}$; and V3 subgroup, a decline in the leucocyte count at $7(7025 / \mu \mathrm{L})$ and $18(7250 / \mu \mathrm{L})$ dpi (Figure 2). The mean leucocyte count in the V4 subgroup declined markedly at $7(5675 / \mu \mathrm{L}), 10(5393 / \mu \mathrm{L}), 14(7270 / \mu \mathrm{L})$, and $18(4530 / \mu \mathrm{L}) \mathrm{dpi}$, as did that in mock pigs at 7 $(7350 / \mu \mathrm{L}), 10(6120 / \mu \mathrm{L}), 14(5510 / \mu \mathrm{L})$, and $18(4940 / \mu \mathrm{L})$ dpi (Figure 2$)$. The mean rectal temperature of the V1 subgroup changed only very slightly $\left(38.7-39.5^{\circ} \mathrm{C}\right)$ after inoculation with virulent CSFV; however, the rectal temperature in the V2 subgroup was $40.0^{\circ} \mathrm{C}$ at $10 \mathrm{dpi}$, and that in the V3 subgroup was $40.3-40.6^{\circ} \mathrm{C}$ at $10-14 \mathrm{dpi}$ (Figure 3). The rectal temperature of pigs in the V4 subgroup and the mock group was high $\left(40.2-41.1^{\circ} \mathrm{C}\right.$ at $3-21 \mathrm{dpi}$ and $40.2-40.7^{\circ} \mathrm{C}$ at $3-10 \mathrm{dpi}$, respectively) (Figure 3).

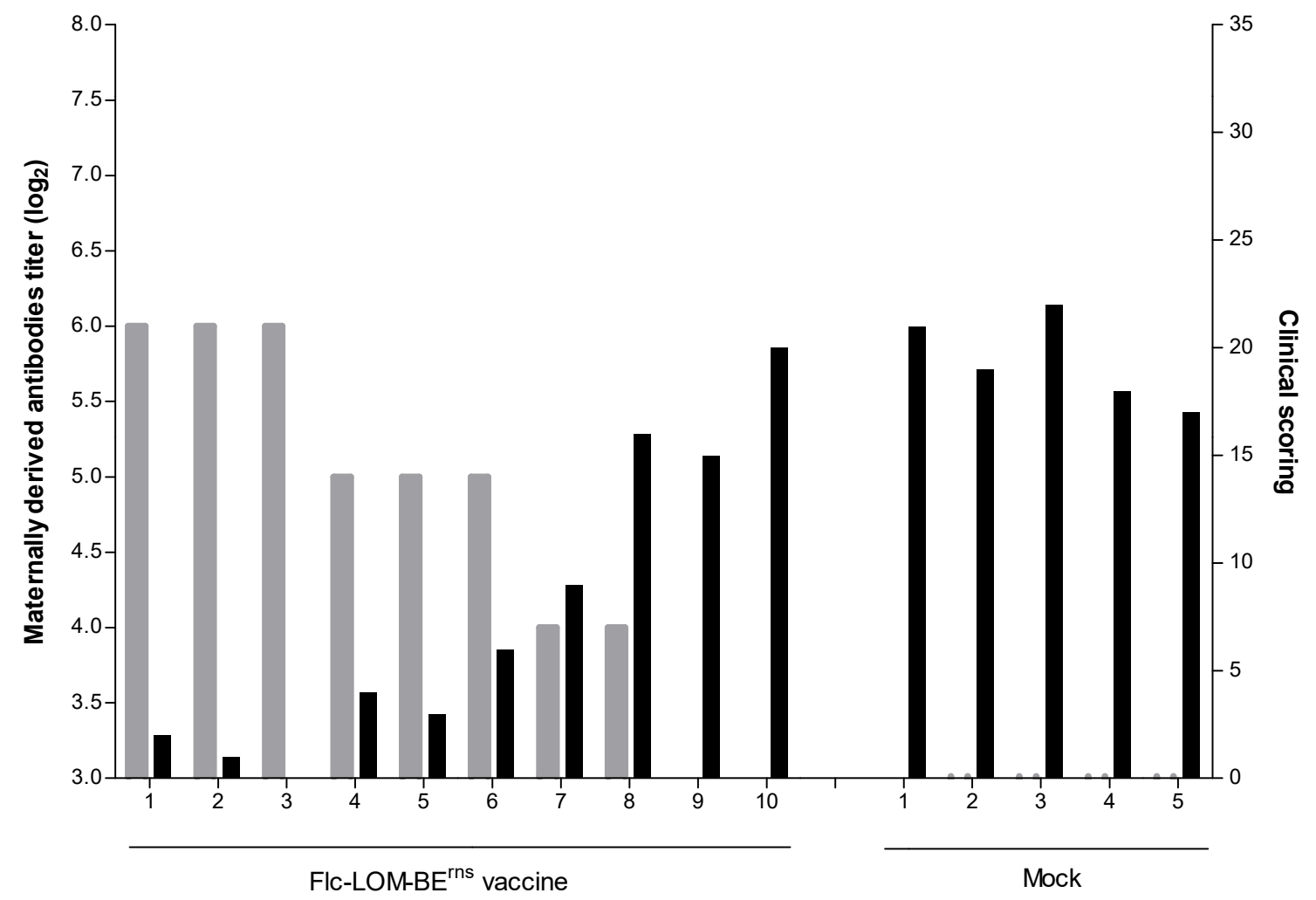

Figure 1. Titers of maternally derive antibodies at the time of challenge and mean clinical signs upon CSFV infection. Pigs acquired passive immunity from sows inoculated with the Flc-LOM-BE ${ }^{\text {rns }}$ vaccine. Other pigs received MDA from sows not inoculated with the Flc-LOM-BE ${ }^{\text {rns }}$ vaccine (Mock). Maternally derived antibody titers are denoted by light gray bars, and the average clinical scores during the experimental period are marked by black bars. 


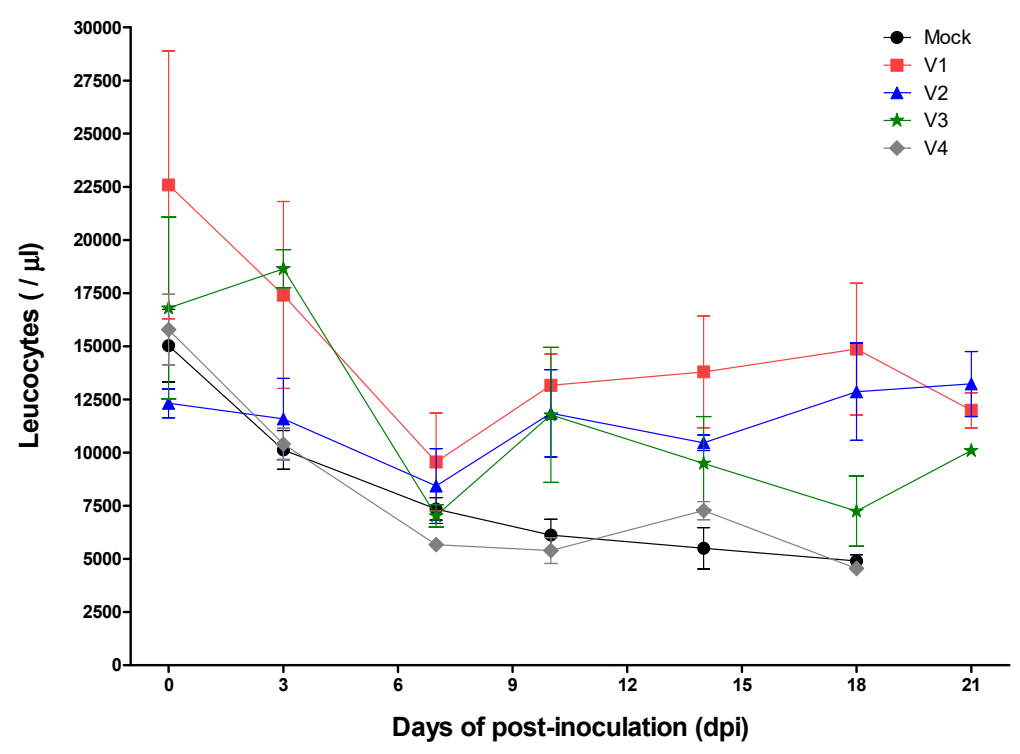

Figure 2. Leucocyte counts post-CSFV infection. Leucocytes from pigs with MDA titers of 6 (V1), 5 (V2), 4 (V3), and $3 \leq$ (V4) $\log _{2}$ or mock controls are denoted by rectangles (red), triangles (blue), stars (green), diamonds (gray), and circles (black), respectively.

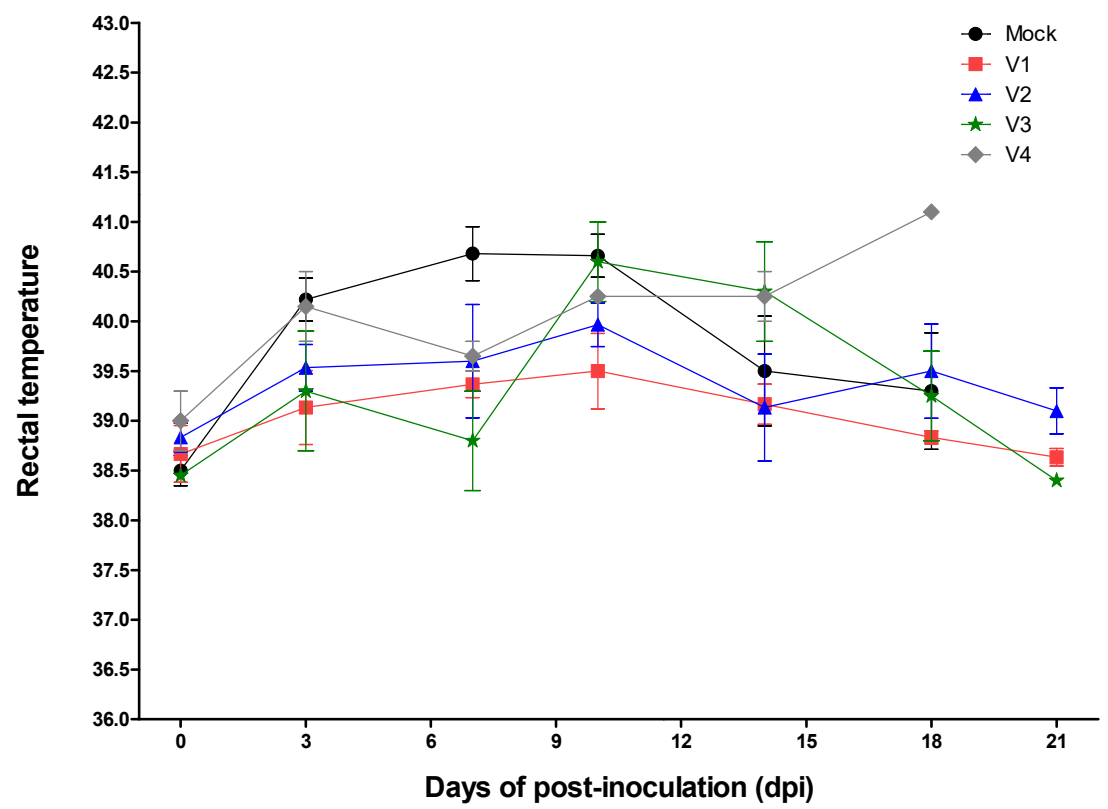

Figure 3. Rectal temperature and maternally derived antibody titers post-CSFV infection. Rectal temperature of pigs with MDA titers of 6 (V1), 5 (V2), 4 (V3), and $3 \leq$ (V4) $\log _{2}$ and of mock control pigs are marked by rectangles (red), triangles (blue), stars (green), diamonds (gray), and circles (black), respectively.

The survival rates of pigs with MDAs from Flc-LOM-BE ${ }^{\text {rns }}$ vaccinated and unvaccinated sows after virulent CSFV challenge were $70 \%$ and $0 \%$, respectively (Table 1 ). All pigs in the V2 and V1 subgroup survived when challenged with virulent CSFV; however, the survival rates for those in the V3 and V4 subgroups were 50\% (1/2) and 0\% (0/2), respectively (Table 1 ). The three pigs died at 18, 20, and 21 days post-CSFV inoculation (dpi), respectively (Table 1). All five pigs in the mock group died between 12 and 19 dpi (Table 1). 


\subsection{Detection of CSFV RNA in Organs}

We performed qRT-PCR to detect CSFV RNA in samples from 11 organs (tonsil, lung, heart, liver, kidney, ileum, cecum, spleen, mesenteric lymph node, inguinal lymph node, and brain) harvested from pigs. No CSFV RNA was detected in any of the organs from the three pigs in the V1 subgroup; however, low RNA copy numbers $\left(2.1-2.9 \log _{10}\right)$ were detected in tonsil, kidney, and spleen from pigs in the V2 subgroup (Table 2). By contrast, CSFV RNA (1.5-4.2 $\log _{10}$ ) was detected in tonsil, lung, heart, kidney, cecum, spleen, mesenteric lymph node, inguinal lymph node, and brain tissue from pigs in the V3 and V4 subgroups. CSFV RNA was also detected (1.4-5.3 $\left.\log _{10}\right)$ in tissue samples from various organs from the five pigs in the mock group (Table 1).

Table 2. CSFV viral copy number in different organs from pigs challenged with CSFV, as detected by qRT-PCR.

\begin{tabular}{|c|c|c|c|c|c|c|c|c|c|c|c|c|c|c|c|}
\hline \multirow{2}{*}{ Group } & \multirow{2}{*}{$\begin{array}{c}\text { Sub } \\
\text { Group }\end{array}$} & \multirow{2}{*}{ Pig ID } & \multirow{2}{*}{$\begin{array}{c}\text { MDA }\left(\log _{2}\right) \\
\text { of Pigs }\end{array}$} & \multirow{2}{*}{$\begin{array}{c}\text { Pig } \\
\text { Age }^{\text {a }}\end{array}$} & \multicolumn{11}{|c|}{ RNA Copy Number $\left(\log _{10}\right)$ from Organ Samples on the Necropsy } \\
\hline & & & & & To $^{b}$ & Lu & $\mathrm{He}$ & Li & $\mathbf{K i}$ & Il & $\mathrm{Ce}$ & $\mathrm{Sp}$ & ML & LN & Br \\
\hline \multirow{10}{*}{$\begin{array}{l}\text { Flc- } \\
\text { LOM- } \\
\text { BE }^{\text {rns }}\end{array}$} & \multirow{3}{*}{ V1 } & 1 & 6 & 42 & - & - & - & - & - & - & - & - & - & - & - \\
\hline & & 2 & 6 & 42 & - & - & - & - & - & - & - & - & - & - & - \\
\hline & & 3 & 6 & 40 & - & - & - & - & - & - & - & - & - & - & - \\
\hline & \multirow{3}{*}{ V2 } & 4 & 5 & 40 & - & - & - & - & - & - & - & - & - & - & - \\
\hline & & 5 & 5 & 46 & 2.2 & - & - & - & - & - & - & - & - & - & - \\
\hline & & 6 & 5 & 46 & 2.5 & - & - & - & 2.9 & - & - & 2.1 & - & - & - \\
\hline & \multirow{2}{*}{ V3 } & 7 & 4 & 53 & 3.1 & - & - & - & - & - & - & 3.4 & 1.5 & 1.9 & - \\
\hline & & 8 & 4 & 53 & 2.7 & - & - & - & 2.6 & - & 2.1 & - & - & 1.5 & - \\
\hline & \multirow{2}{*}{$\mathrm{V} 4$} & 9 & $\leq 3$ & 60 & 3.6 & - & 2.7 & - & 3.5 & - & - & - & 2.3 & 2.8 & 2.4 \\
\hline & & 10 & $\leq 3$ & 60 & 2.9 & 2.8 & - & - & 4.2 & - & - & 2.5 & 4.2 & 3.7 & - \\
\hline \multirow{5}{*}{$\begin{array}{l}\text { Unvacc } \\
\text { inated }\end{array}$} & \multirow{5}{*}{ Mock } & 1 & $\leq 3$ & 48 & 3.7 & - & - & - & 3.4 & - & - & 4.2 & - & 4.1 & 2.9 \\
\hline & & 2 & $\leq 3$ & 48 & 4.6 & 2.8 & 1.4 & - & 4.5 & - & - & - & - & - & - \\
\hline & & 3 & $\leq 3$ & 55 & - & - & - & - & 2.1 & - & 3.5 & 5.3 & 4.6 & 3.2 & - \\
\hline & & 4 & $\leq 3$ & 55 & 5.3 & - & - & - & - & - & - & 4.6 & 3.8 & - & 3.2 \\
\hline & & 5 & $\leq 3$ & 55 & 2.9 & 4.2 & - & - & 3.3 & - & - & 4.1 & 2.8 & 3.6 & - \\
\hline
\end{tabular}

${ }^{a}$ Age: pig age on the day of challenge. ${ }^{\mathrm{b}} \mathrm{To}$, tonsil; Lu, lung; He, heart; Li, liver; Ki, kidney; Il, ileum; Ce, cecum;

$\mathrm{Sp}$, spleen; ML, mesenteric lymph node; $\mathrm{LN}$, inguinal lymph node; $\mathrm{Br}$, brain.

\subsection{CSFV $E^{\text {rns }}$ and BVDV E $E^{\text {rns }}$ Antibody Titers}

The CSF $E^{\text {rns }}$ antibody titer of all 10 pigs with MDAs, at the day of challenge was negative (serological neutralizing antibody titer, or $\mathrm{S} / \mathrm{N}$ value, $0.67-0.81$ ) according to a CSF $\mathrm{E}^{\text {rns }}$ ELISA. However, a BVDV $E^{\text {rns }}$ ELISA detected BVDV $\mathrm{E}^{\text {rns }}$ antibodies in $70 \%(7 / 10)$ of the pigs (S/P value, $0.63-0.85$ ) (Table 3). On the day of necropsy, the CSF $E^{\text {rns }} \mathrm{S} / \mathrm{N}$ values of pigs with MDAs (induced by the Flc-LOM-BE ${ }^{\text {rns }}$ vaccine) revealed $50 \%(5 / 10)$ of positive antibody ( $\mathrm{S} / \mathrm{N}$ value, $\left.0.32-0.45\right)$; however, the BVDV $E^{\text {rns }} \mathrm{S} / \mathrm{P}$ values showed that only $40 \%(4 / 10)$ have positive antibodies (S/P value: $0.60-0.73$ ) (Table 3). The CSF $E^{\text {rns }} \mathrm{S} / \mathrm{N}$ and the BVDV $\mathrm{E}^{\text {rns }} \mathrm{S} / \mathrm{P}$ values of pigs from unvaccinated sows (Mock group) showed all negative at $0 \mathrm{dpi}$ and on the day of necropsy after virulent CSFV challenge (Table 3 ). At the time of necropsy, there was either a very small decrease or no change in MDA serum neutralization antibody titers after inoculation with virulent CSFV (Table 3). 
Table 3. Comparison of MDA, CSFV E ${ }^{\text {rns }}$, and bovine viral diarrhea virus (BVDV) $E^{\text {rns }}$ antibody titers before CSFV inoculation and at the time of necropsy after challenge.

\begin{tabular}{|c|c|c|c|c|c|c|c|c|c|c|}
\hline \multirow{2}{*}{ Group } & \multirow{2}{*}{ Subgroup } & \multirow{2}{*}{ Pig ID } & \multirow{2}{*}{ Pig Age ${ }^{a}$} & \multicolumn{3}{|c|}{ Day of Challenge (0 dpi) } & \multicolumn{4}{|c|}{ Day of Necropsy } \\
\hline & & & & MDA $^{b}$ & CSF E $E^{\text {rns }}$ & BVDV $E^{\text {rns }}$ & SN & $\mathrm{CSF}^{\mathrm{rns}}$ & BVDV E ${ }^{\text {rns }}$ & dpi \\
\hline \multirow{10}{*}{ Flc-LOM-BE ${ }^{\text {rns }}$} & \multirow{3}{*}{ V1 } & 1 & 42 & 6 & 0.81 & 0.76 & 6 & 0.36 & 0.68 & 21 \\
\hline & & 2 & 42 & 6 & 0.73 & 0.85 & 7 & 0.42 & 0.73 & 21 \\
\hline & & 3 & 40 & 6 & 0.76 & 0.77 & 6 & 0.32 & 0.60 & 21 \\
\hline & \multirow{3}{*}{$\mathrm{V} 2$} & 4 & 40 & 5 & 0.68 & 0.83 & 6 & 0.45 & 0.72 & 21 \\
\hline & & 5 & 46 & 5 & 0.71 & 0.75 & 5 & 0.39 & 0.58 & 21 \\
\hline & & 6 & 46 & 5 & 0.67 & 0.84 & $\leq 3$ & 0.73 & 0.36 & 21 \\
\hline & \multirow{2}{*}{ V3 } & 7 & 53 & 4 & 0.79 & 0.55 & $\leq 3$ & 0.81 & 0.31 & 21 \\
\hline & & 8 & 53 & 4 & 0.69 & 0.63 & $\leq 3$ & 0.62 & 0.45 & 20 \\
\hline & \multirow{2}{*}{$\mathrm{V} 4$} & 9 & 60 & $\leq 3$ & 0.77 & 0.40 & $\leq 3$ & 0.85 & 0.18 & 18 \\
\hline & & 10 & 60 & $\leq 3$ & 0.72 & 0.51 & $\leq 3$ & 0.79 & 0.33 & 21 \\
\hline \multirow{5}{*}{ Unvaccinated } & \multirow{5}{*}{ Mock } & 1 & 48 & $\leq 3$ & 0.89 & 0.42 & $\leq 3$ & 0.76 & 0.25 & 17 \\
\hline & & 2 & 48 & $\leq 3$ & 0.92 & 0.31 & $\leq 3$ & 0.85 & 0.33 & 19 \\
\hline & & 3 & 55 & $\leq 3$ & 0.73 & 0.18 & $\leq 3$ & 0.87 & 0.42 & 16 \\
\hline & & 4 & 55 & $\leq 3$ & 0.90 & 0.36 & $\leq 3$ & 0.82 & 0.19 & 12 \\
\hline & & 5 & 55 & $\leq 3$ & 0.82 & 0.28 & $\leq 3$ & 0.93 & 0.32 & 15 \\
\hline
\end{tabular}

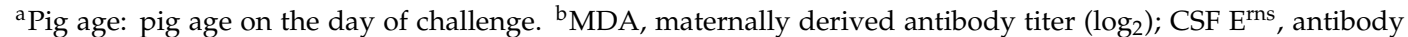
ELISA ( $\mathrm{S} / \mathrm{N}$ value: $>0.5$ negative and $0.5 \leq$ positive); BVDV $\mathrm{E}^{\mathrm{rns}}$, antibody ELISA (S/P value: $\geq 0.6$ positive and $0.6<$ negative); $\mathrm{S} / \mathrm{N}$, serological neutralizing antibody titer $\left(\log _{2}\right)$; dpi, day post-CSFV inoculation. Positive samples for the CSFV $E^{\text {rns }}$ and BVDV $E^{\text {rns }}$ are marked in bold.

\section{Discussion}

CSFV-specific antibody titers of piglets from immunized sows were declining quickly during the early postnatal weeks. It has been proven that dilution of the MDAs due to the growth of the piglets was the main cause for the decay of the MDAs [15]. In association with the growth of the piglets, the increased catabolism may also affect the decline of the MDAs. The decay of reactivities seemed to be almost linear with clear negative ELISA results at about 10 weeks post farrowing [12]. Depending on the age of piglets, MDAs may have different effects on the development of antibodies by live attenuated CSFV vaccination. The protection rate at the end of the economic life of piglets with colostral antibodies was $50 \%$ when they received live attenuated vaccine inoculatation at the age of 7 days, whereas a 100\% protection rate was shown when vaccination was given at the age of 2 months [8]. A previous study suggested that vaccination with the Chinese strain is fully effective in piglets that have passive immunity when they are 30-60 days old [7]. Several other reports also indicated that the level of anti-CSFV antibodies titer of 32 -fold $\left(5 \log _{2}\right)$ can provide an adequate protection to pigs actively vaccinated with C-strain [9,16], CP7_E2alf [17], or rPRVTJ-delgE/gI-E2 [18]. The piglets with MDAs originating from vaccination of the sows with C-strain were provided full to partial protection against lethal CSFV challenge, depending on the age of pigs $[19,20]$. MDAs from the sows immunized three times with CP7_E2alf did not protect piglets against CSFV "Koslov" strain challenge, and the piglets showed severe clinical signs [10]. The passive protection provided by MDAs derived from the rAdV-SFV-E2-immunized sow was also observed in the C-strain but not in CP7_E2alf. The serum neutralization titer of the anti-CSFV antibody was 1:49 in the piglets (around the 5-week-old age) born from the sow immunized with $4 \times 10^{6} \mathrm{TCID}_{50}$ rAdV-SFV-E2, which can confer a complete protection to piglets [14]. Another study reported that piglets inoculated with virulent CSFV (Shimen strain) at the age of 56 days received MDAs (from sows inoculated with the C-strain vaccine); however, they did not show protection at an MDA titer of $18 \pm 3$ (serum neutralization antibody titer) [11]. Similar results of no protection were also shown when five pigs with an MDA titer of $16 \pm 0$ (serum neutralization antibody titer) from sows vaccinated with anti-rAdV-SFV-E2 were challenged with the Shimen strain [11].

Interestingly, when the serum neutralization test (SNT) was performed using the virulent strains (YC11WB and ALD) and vaccine strain (LOM) to test the MDA titers of piglets, the MDA titer of the V1-3 subgroups ( $>3 \log _{2}$ ) were the same, but the mock group and V4 subgroup $\left(\leq 3 \log _{2}\right)$ showed 
slightly different results. Specifically, in the SNT using ALD and YC11WB strains, Pig ID 9 and 10 of piglets of Flc-LOM-BE ${ }^{\text {rns }}$ vaccinated sows were $<2 \log _{2}$ and $3 \log _{2}$, whereas all piglets of unvaccinated sows were $<2 \log _{2}$. In addition, in the SNT by LOM vaccine strain, Pig ID 9 and 10 of piglets of Flc-LOM-BE ${ }^{\text {rns }}$ vaccinated sows were all $3 \log _{2}$, and all piglets of unvaccinated sows showed the titer range from $<2$ to $3 \log _{2}$.

In the detection of MDAs by the SNT, we have used the SN titer of $3 \log _{2}$ as a threshold and less than $3 \log _{2}$ was considered as negative. This threshold was selected considering the SN titers obtained from control piglets born from unvaccinated sows and the high specificity of serum neutralization assay by immunostaining reading. This decision was made because CSFV vaccination has been mandatory in South Korea for 40 years, and it is possible that some residual levels of MDAs are still detected even in farms that had stopped the vaccination of their sows for a long time.

There are differences among farms and even individual sows with respect to the time that MDA decays. In accordance with recommendations by the South Korea government, Korean pig farmers give pigs one shot (at 55-70 days old) or two shots (at 40 days old and 60 days old) of CSF vaccine (LOM strain) [21]. Anti-CSFV antibodies from slaughtered pigs in South Korea showed a positive rate over 95\% each year, which indicates that our CSF vaccination schedules are effective [22]. Our results with the Flc-LOM-BE ${ }^{\text {rns }}$ vaccination of sows indicated that when offspring were vaccinated around 45-60 days old, MDA may not provide full protection against virulent CSFV, which supports the vaccination schedules of the LOM CSFV vaccine. Therefore, an active Flc-LOM-BE ${ }^{\text {rns }}$ vaccination schedule in pigs also needs to consider these periods of MDA decay time to induce efficient lifelong protection. To select an adequate timeline for an active vaccination schedule for Flc-LOM-BE ${ }^{\text {rns }}$ in pigs, further animal experiments may be needed.

Highly virulent, moderately virulent, and avirulent strains of CSFV were tested in standardized animal experiments to confirm their virulence and were used to search for in vitro parameters allowing the differentiation of strains according to their virulence; these observations were also characterized by a newly developed 10 clinical score determination scheme [23]. Clinical scores from 10 parameters were calculated to a maximum of 30 per day [23]. Based on the previously reported clinical sign scoring system, we added the scores for the leucopenia and the dead, and the clinical scores for 12 parameters were summed during the experiment to measure the average. Here, we found that the mean clinical scores of pigs in the V1 and V2 subgroups (6 and $5 \log _{2}$ MDAs) infected with virulent CSFV were 1 and 4.3 , respectively. When pigs received a clinical score of less than 3 , it was considered as complete protection against virulent CSFV. The mean rectal temperature and leucocyte counts in the V1 subgroup pigs was $<40^{\circ} \mathrm{C}$ and $>8000 / \mu \mathrm{L}$, respectively; however, those in the V2 subgroup increased their clinical score temporarily $\left(>40^{\circ} \mathrm{C}\right.$ and $>8000 / \mu \mathrm{L}$, respectively). No pigs in the V1 subgroup shed the virus via nasal discharges or feces, although CSFV RNA was detected in nasal and fecal swabs from one of the pigs in the V2 subgroup. At the time of necropsy, no CSFV RNA was detected in 11 organs from the V1 subgroup pigs, whereas in two of the three pigs in the V2 subgroup, viral RNA was detected in tonsil, kidney, and spleen samples. Therefore, our data indicated that for a passive immune response induced by MDA, the protective antibody titer should be at least $6 \log _{2}$ or more.

The different antibodies that function as a DIVA vaccine (Flc-LOM-BE ${ }^{\text {rns }}$ strain) in this study were detected in MDAs: all negative CSF $E^{\text {rns }} \mathrm{S} / \mathrm{N}$ values and all positive BVDV $\mathrm{E}^{\mathrm{rns}} \mathrm{S} / \mathrm{P}$ values (3 pigs of $5 \log _{2}$ MDAs). When pigs infected with virulent CSF were subjected to necropsy, three pigs with an MDA titer of $6 \log _{2}$ had antibodies specific for both CSF $E^{\text {rns }}$ and BVDV E ${ }^{\text {rns }}$ at 21 dpi; however, three pigs with an MDA titer of $5 \log _{2}$ showed both positive or negative values at $21 \mathrm{dpi}$. A previous study showed that pregnant sows inoculated with the Flc-LOM-BE ${ }^{\text {rns }}$ vaccine were anti-CSF $E^{\text {rns }}$ antibody-negative and anti-BVDV $E^{\text {rns }}$ antibody-positive [4]. However, after challenge with virulent CSFV, they were anti-CSF $E^{\text {rns }}$ antibody-positive [4]. In other reports, Erns-specific antibodies were induced in some of the piglets challenged at 15 days of post-challenge (dpc) [14] and even suggested to test anti-Erns antibodies at $15 \mathrm{dpc}$ or later for better observation [10]. 
Although a small-scale animal experiment was performed in this study due to the relevance of animal ethical approval, our data showed a correlation with the defense ability and various levels of MDA titers induced by Flc-LOM-BE ${ }^{\text {rns }}$ vaccination in sows. Thus, this study can be considered as a first report on the efficiency of MDA against virulent CSFV challenge, and further studies are needed to determine more detailed aspects of the minimum MDA titers to achieve sufficient protection in young pigs.

In conclusion, pigs that received passive immunity via MDAs ( $\geq 6 \log _{2}$ titer) from sows immunized with the Flc-LOM-BE ${ }^{\text {rns }}$ vaccine were protected against virulent CSFV challenge. The Flc-LOM-BE ${ }^{\text {rns }}$ vaccine successfully fulfilled the function of differential diagnosis when passive immunity was induced by MDA from immunized sows.

\section{Materials and Methods}

\subsection{Animal Experiments}

In animal experiments, sows were inoculated with the SuiShot ${ }^{\circledR}$ CSFV Marker-L (Flc-LOM-BE ${ }^{\text {rns }}$ strain) vaccine of the CAVAC (Choong Ang Vaccine Laboratories Co., Ltd.). Pigs born from sows that were inoculated with or without the Flc-LOM-BE ${ }^{\text {rns }}$ vaccine were divided into two groups and challenged with virulent CSFV at 40, 42, 46, 48, 53, 55, and 60 days of life with different MDA titers (Table 1). Slightly different aged pigs with various levels of MDA were used in the experiment. Ten pigs obtained MDAs from five sows inoculated with the Flc-LOM-BE ${ }^{\text {rns }}$ vaccine, and five pigs obtained MDAs from two sows that did not receive the Flc-LOM-BE ${ }^{\text {rns }}$ vaccine (Table 1). All pigs were tested for MDA level from serum obtained at the day of challenge. For the challenge of virulent CSFV, YC11WB strain subgenotype $2.1 \mathrm{~d}$ was injected intranasally $\left(2 \mathrm{ml} ; 10^{5.0} \mathrm{TCID} \mathrm{D}_{50} / \mathrm{mL}\right)$, and the pigs were observed for 3 weeks. At $0,3,7,10,14,18$, and 21 days post inoculation (dpi), blood samples were collected to investigate levels of MDAs, the CSFV RNA copy number $\left(\log _{10}\right)$, and the number of leucocytes. The clinical score was determined based on 10 parameters (liveliness, body tension, body shape, breathing, walking, skin, eyes, appetite, defecation, and leftovers in the feeding trough), as described previously [23]. The clinical scoring system is 0 (normal), 1 (slightly altered), 2 (showing distinct clinical signs), and 3 (showing severe CSF clinical signs) according to each parameter. Briefly, the clinical score for each of the 3 values for these 10 parameters are as follows: dormant, will not stand up; cramps; emaciated, backbone and ribs visible, head size too big compared to body size; frequency $>30 / \mathrm{min}$, breathing through open mouth; massive lameness, unable to walk; black-red discoloration of skin, no sensitivity, large hemorrhages in skin; highly inflamed, purulent secretion, accentuated blood vessels; does not eat at all, shows no interest for food; no feces, mucus in rectum, or watery or bloody diarrhea; trough still full, nothing eaten. The clinical score of 0,1 , or 2 was determined by the degree of the severity. Additionally, we counted the days of leucopenia $(<8000 / \mathrm{uL})$, scoring 1 for one day and 3 for the death. The clinical score was measured daily during the experiment period, and only the day the pig died was added with a clinical score of 3 . The mean clinical score was measured as the average of the clinical score levels accumulated during the experimental period. Protection was classified as none (total clinical score $\geq 11$ ), weak (total clinical score 4-10), or strong (total clinical score 0-3).

After virulent CSFV challenge, pigs were dead within 21 days post inoculation. Necropsy was performed at the time of death, and pigs that survived throughout the observation period were necropsied at 21 days post inoculation. Eleven organs (tonsil, lung, heart, kidney, cecum, spleen, mesenteric lymph node, inguinal lymph node, and brain) were collected by necropsy, and viral copy number were detected by qRT-PCR.

\subsection{Serum Neutralization Test and $q R T-P C R$}

To detect CSF-specific serum neutralization antibodies, a neutralization peroxidase-linked antibody (NPLA) assay was performed according to the standards manual of the World Organization for Animal Health [24]. According to the OIE criteria, an initial serum dilution to antibodies examination performed 
two-fold dilution. Two virulent CSF viruses (ALD strain and YC11WB strain) and one CSF vaccine strain (LOM) using the NPLA reacted $200 \mathrm{TCID}_{50} / \mathrm{mL}$ per 96 -well plate. Less than 3 fold $\left(3 \leq \log _{2}\right)$ neutralizing antibodies was considered as negative. The VDx ${ }^{\circledR}$ CSFV qRT-PCR (Median Diagnostic Co., Cat No. NS-CSF-31, Cheonchen, South Korea), which employs TaqMan probes, detects the CSFV 5'UTR with high specificity, but it does not detect BVDV or border disease virus, which also belongs to the genus Pestivirus. The assay was performed as described previously [25].

\subsection{CSFV $E^{r n s}$ and BVDV BE $E^{r n s}$ ELISAs}

The CSFV $E^{\text {rns }}$ and BVDV $E^{\text {rns }}$ ELISAs used to detect specific antibodies were performed as described previously [4]. The VDPro ${ }^{\circledR}$ CSF Erns Ab b-ELISA (MEDIAN Diagnostic Co., Cat No. ES-CSF-05, Korea), a competition ELISA designed to detect the $\mathrm{E}^{\mathrm{rns}}$ protein, was also used to determine the $\mathrm{S} / \mathrm{N}$ value ( $>0.5$ negative and $0.5 \leq$ positive). The VDPro ${ }^{\circledR}$ BVDV Erns Ab i-ELISA (MEDIAN Diagnostic Co., Cat No. ES-BVD-01, Korea), which is based on the E2 protein, provided an $\mathrm{S} / \mathrm{P}$ value $(\geq 0.6$ positive and $0.6<$ negative $)$.

\subsection{Ethical Approval}

The authors confirm that the work complies with the ethical policies of the journal. The work was approved by the Institutional Animal Care and Use Committee of the Animal and Plant Quarantine Agency (APQA) (Approval Number: 2019-481).

Author Contributions: Conceptualization, S.C. and B.-K.P.; methodology, J.S., K.-S.K., S.S., R.M.C., and B.-I.J.; writing/review and editing, B.-H.H. and D.-J.A. All authors have read and agree to the published version of the manuscript.

Funding: This project was supported by grants (Project Code no. B-1543083-2019-20-01) from the Animal and Plant Quarantine Agency, Republic of Korea.

Acknowledgments: Not applicable.

Conflicts of Interest: The authors declare no conflict of interest.

\section{References}

1. Edwards, S.; Fukusho, A.; Lefèvre, P.C.; Lipowski, A.; Pejsak, Z.; Roehe, P.; Westergaard, J. Classical swine fever: The global situation. Vet. Microbiol. 2000, 73, 103-119. [CrossRef]

2. Moennig, V. The control of classical swine fever in wild boar. Front. Microbiol. 2015, 6, 1211. [CrossRef] [PubMed]

3. Fritzemeier, J.; Teuffert, J.; Greiser-Wilke, I.; Staubach, C.; Schlüter, H.; Moennig, V. Epidemiology of classical swine fever in Germany in the 1990s. Vet. Microbiol. 2000, 77, 29-41. [CrossRef]

4. Lim, S.I.; Choe, S.; Kim, K.S.; Jeoung, H.Y.; Cha, R.M.; Park, G.S.; Shin, J.; Park, G.N.; Cho, I.S.; Song, J.Y.; et al. Assessment of the efficacy of an attenuated live marker classical swine fever vaccine (Flc-LOM-BE ${ }^{\text {rns }}$ ) in pregnant sows. Vaccine 2019, 37, 3598-3604. [CrossRef]

5. Insel, R.A.; Amstey, M.; Woodin, K.; Pichichero, M. Maternl immunization to prevent infectious diseases in the neonate or infant. Int. J. Technol. Assess. Health Care 1994, 10, 143-153. [CrossRef]

6. Pravieux, J.J.; Poulet, H.; Charreyre, C.; Juillard, V. Protection of newboarn animals through maternal immunization. J. Comp Pathol. 2007, 137 (Suppl.1), S32-S34. [CrossRef]

7. Mierzejewska, M.; Tereszczuk, S.; Corthier, G.; Aynaud, J.M. Hog cholera virus: Influence of colostral passive antibody on immune response of pig following vaccination with the rabbit adapted Chinese strain (author's transl). Ann. Rech Vet. 1977, 8, 227-240.

8. Précausta, P.; Kato, F.; Brun, A. Hog cholera: Active immunity conferred by the Chinese strain vaccine to young pigs born to immune sows. Dev. Biol. Stand. 1978, 41, 367-379.

9. Terpstra, C.; Wensvoort, G. The protective value of vaccine-induced neutralising antibody titres in swine fever. Vet. Microbiol. 1988, 16, 123-128. [CrossRef]

10. Eblé, P.L.; Quak, S.; Geurts, Y.; Moonen-Leusen, H.W.; Loeffen, W.L. Efficacy of CSF vaccine CP7_E2alf in piglets with maternally derived antibodies. Vet. Microbiol. 2014, 174, 27-38. [CrossRef] 
11. Xia, S.L.; Xiang, G.T.; Lei, J.L.; Du, M.; Wang, Y.; Zhou, M.; Liu, Y.; Ji, S.; Wang, Y.L.; Luo, Y.; et al. Efficacy of the marker vaccine rAdV-SFV-E2 against classical swine fever in the presence of maternally derived antibodies to rAdV-SFV-E2 or C-strain. Vet. Microbiol. 2016, 196, 50-54. [CrossRef]

12. Schröder, C.; Dräger, C.; Aebischer, A.; Dähnert, L.; Breidenstein, C.; Mamerow, S.; Leidenberger, S.; Beer, M.; Blome, S. Kinetics of maternally derived antibodies upon intramuscular vaccination against classical swine fever with Suvaxyn ${ }^{\circledR}$ CSF Marker (CP7_E2alf). Vet. Microbiol. 2016, 196, 14-17. [CrossRef] [PubMed]

13. Farsang, A.; Lévai, R.; Barna, T.; Fábián, K.; Blome, S.; Belák, K.; Bálint, Á.; Koenen, F.; Kulcsár, G. Pre-registration efficacy study of a novel marker vaccine against classical swine fever on maternally derived antibody positive (MDA+) target animals. Biologicals 2017, 45, 85-92. [CrossRef] [PubMed]

14. Xia, S.L.; Du, M.; Lei, J.L.; Liu, Y.; Wang, Y.; Ji, S.; Xiang, G.T.; Li, L.F.; Cong, X.; Luo, Y.; et al. Piglets with maternally derived antibodies from sows immunized with rAdV-SFV-E2 were completely protected against lethal CSFV challenge. Vet. Microbiol. 2016, 190, 38-42. [CrossRef]

15. Curtis, J.; Bourne, F.J. Half-lives of immunoglobulins IgG, IgA and IgM in the serum of new-born pigs. Immunology 1973, 24, 147-155.

16. Reimann, I.; Depner, K.; Utke, K.; Leifer, I.; Lange, E.; Beer, M. Characterization of a new chimeric marker vaccine candidate with a mutated antigenic E2- epitope. Vet. Microbiol. 2010, 142, 45-50. [CrossRef]

17. Reimann, I.; Depner, K.; Trapp, S.; Beer, M. An avirulent chimeric pestivirus with altered cell tropism protects pigs against lethal infection with classical swine fever virus. Virology 2004, 322, 143-157. [CrossRef]

18. Wang, Y.; Xia, S.L.; Lei, J.L.; Cong, X.; Xiang, G.T.; Luo, Y.; Sun, Y.; Qiu, H.J. Dose-dependent pathogenicity of a pseudorabies virus variant in pigs inoculated via intranasal route. Vet. Immunol. Immunopathol. 2015, 168, 147-152. [CrossRef]

19. Terpstra, C. The immunity against challenge with swine fever virus of piglets from sows vaccinated with C-strain virus. Tijdschr. Diergeneeskd. 1977, 102, 1293-1298.

20. Rangelova, D.; Nielsen, J.; Strandbygaard, B.; Koenen, F.; Blome, S.; Uttenthal, Å. Efficacy of marker vaccine candidate CP7_E2alf in piglets with maternally derived C-strain antibodies. Vaccine 2012, 30, 6376-6381. [CrossRef]

21. An, D.J.; Lim, S.I.; Choe, S.; Kim, K.S.; Cha, R.M.; Cho, I.S.; Song, J.Y.; Hyun, B.H.; Park, B.K. Evolutionary dynamics of classical swine fever virus in South Korea: 1987-2017. Vet. Microbiol. 2018, 225, 79-88. [CrossRef] [PubMed]

22. Song, J.Y.; Lim, S.I.; Jeoung, H.Y.; Choi, E.J.; Hyun, B.H.; Kim, B.; Kim, J.J.; Shin, Y.K.; dela Pena, R.C.; Kim, J.B.; et al. Prevalence of Classical Swine Fever Virus in Domestic Pigs in South Korea: 1999-2011. Transbound Emerg. Dis. 2013, 60, 546-551. [CrossRef]

23. Mittelholzer, C.; Moser, C.; Tratschin, J.; Hofmann, M.A. Analysis of classical swine fever virus replication kinetics allows differentiation of highly virulent from avirulent strains. Vet. Microbiol. 2000, 74, 293-308. [CrossRef]

24. Drew, T. Classical swine fever (hog cholera). In Manual of Diagnostic Tests and Vaccines for Terrestrial Animals: Mammals, Birds and Bees, 6th ed.; Office International des Epizooties (OIE), Ed.; OIE: Paris, France, 2008; pp. 1092-1106.

25. Choe, S.; Kim, J.H.; Kim, K.S.; Song, S.; Cha, R.M.; Kang, W.C.; Kim, H.J.; Park, G.N.; Shin, J.; Jo, H.N.; et al. Adverse Effects of Classical Swine Fever Virus LOM Vaccine and Jeju LOM Strains in Pregnant Sows and Specific Pathogen-Free Pigs. Pathogens 2019, 23, 18. [CrossRef] [PubMed]

(C) 2020 by the authors. Licensee MDPI, Basel, Switzerland. This article is an open access article distributed under the terms and conditions of the Creative Commons Attribution (CC BY) license (http://creativecommons.org/licenses/by/4.0/). 